\title{
EFFECT OF THE TEMPERATURE ON THE MODAL PROPERTIES OF A STEEL RAILROAD BRIDGE
}

\author{
Michal VENGLÁR ${ }^{1 *}$, Katarína LAMPEROVÁ ${ }^{1}$
}

\begin{abstract}
The article is devoted to a study of the impact of various environmental conditions on modal parameters, such as natural frequencies and damping ratios. The modal analysis has been performed using the Stochastic Subspace Identification (SSI) method of measuring data every month on the same steel bridge structures located on an important railroad route from Prague (the Czech Republic) to Košice (Slovakia). The structure is approximately $60 \mathrm{~m}$ long, and the bearing structure is formed by two arch trusses. The bridge was exposed to ambient vibrations as well as to vibrations caused by a train passage. Accelerations and temperatures (the temperature of the air and the structure) were logged during the measurements. Natural frequencies were obtained from these acceleration data using the SSI method and processed into graphs of the dependencies between the natural frequencies and temperatures. Some statistical procedures were also applied.
\end{abstract}

\section{Address}

1 Dept. of Structural Mechanics, Faculty of Civil Engineering, Slovak University of Technology in Bratislava, Bratislava, Slovakia

* Corresponding author: michal.venglar@stuba.sk

\section{Key words}

- Modal analysis,

- Structural health monitoring,

- Steel bridge,

- Natural frequency,

- System identification,

- Temperature.

\section{INTRODUCTION}

Structural Health Monitoring (SHM) has been achieving more attention from research teams around the world in recent years. This is as a result of many factors, e.g., improvements in sensing technologies, the deteriorating condition of bridges and requirements for greater safety on roads/rails and footbridges, Kala et al. (2010). One part of SHM can be considered to be damage detection. When accelerations or displacements are measured, we can speak about vibration-based damage detection methods. The basics of SHM using vibration-based methods are that the dynamic response of the structure depends on the mass, stiffness, and damping values. In order to detect deterioration (changes in stiffness, the mass, or damping), it is necessary to use an inverse approach, i.e. that damage can be found from changes in the dynamic response as in Finotti et al. (2019), or Giordano et al. (2021). Experimental modal analysis (Sridhar et al., 2019; Papai et al., 2013) or operational modal analysis (Moaveni et al., 2012) can be undertaken in order to obtain dynamic data. Many studies such as Mosavi et al. (2012), Furtmuller and Adam (2017), Tian et al. (2017) and Christian et al. (2019) have investigated the impact of changing environmental conditions (mainly the effect of temperatures) on modal parameters (natural frequencies, mode shapes or damping ratios). In each of the mentioned studies, a different approach to investigating temperature effects was chosen.

In addition, Behmanesh and Moaveni (2016) have calibrated a model using a function (Young's modulus of concrete) of temperature according to the ambient temperature measured during the investigation period. Other numerical simulations of environmental effects were done by Shokrani et al. (2016) when the whole process was only performed on a virtual four-span bridge. Avendaño Valencia et al. (2017) presented a case study on the Humber Bridge in the UK, where various sensors were deployed, e.g., an accelerometer, GPS antennas, inclinometers, and extensometers. In addition, environmental conditions (temperatures and wind speeds) have been measured for three years. Long-term monitoring of a building (a bell tower in Italy) using accelerometers and temperature sensors was conducted by Ubertini et al. (2017). They found a correlation between natural frequencies and temperatures for five frequencies. Zhou and Yi (2014) 
stated that some prediction models have already been prepared, but the models cannot be used in a general way but only on a specific structure. As can be seen, this research field is still developing.

These studies are crucial in order to apply damage detection methods correctly. Kita et al. (2019) stated that the removal of the effect of temperature represents a key step for damage detection. Xia et al. (2012) has stated that it is possible that changes caused by temperature can have a greater impact on natural frequencies than the damage itself and can lead to inaccurate damage detection. Thus, the article is dedicated to studying environmental impacts on the modal parameters of a steel truss bridge.

\section{MEASURED STRUCTURE: A STEEL TRUSS BRIDGE}

The railway bridge examined is located in the northern part of Slovakia and connects two banks over the river Vah. There are two bridge structures, one for each of two railway tracks (T1, T2), and these bridge structures consist of three simply supported objects or a total of six (Fig. 1). The truss bridges have a span of $57.4 \mathrm{~m}(\mathrm{O} 2)$. There are also two girder bridges on the sides with a span of $29.4 \mathrm{~m}$ $(\mathrm{O} 1, \mathrm{O} 3)$, but a study of the effect of temperatures on them has yet not been done.

The bridges (O2) are riveted steel arch trusses. The distance between the two trusses (the width) is $5.9 \mathrm{~m}$. The height of the structure varies up to $8 \mathrm{~m}$. The open deck consists of a floor beam at $4.9 \mathrm{~m}$ intervals in the inner parts of the structures and at a $4.2 \mathrm{~m}$ distance in the outer parts. The stringers have an axial distance of $1.8 \mathrm{~m}$.

\section{SETUP OF THE MEASUREMENTS}

A complex measurement system, similar to that used in Sokol et al. (2020) and Venglar and Sokol (2020), using National Instru-

ments equipment was employed for the repeated measurements. The main part of the system is NI cRIO 9067 (a data logger) with up to four NI 9234 modules. The NI 9234 input module represents an analogue-to-digital converter which is able to measure accelerations. Up to 16 sites can be measured when up to four modules are plugged into the system. A NI 9211 input module is also an important part of the system. A SENSIT type TG4 thermocouple is connected to the module for the measurement of the air temperature, as well as the structural temperature, using contact temperature sensors (SENSIT type TCS190) with the module NI 9211. Three temperature sensors and nine accelerometers were used simultaneously. Accelerations in the Z-direction (vertical) were measured with six sensors (labelled with a black arrow); accelerations in the Y-direction (lateral) were measured with three sensors (labelled with a red arrow). One air and one contact temperature sensor were situated close to the "C" and "D" accelerometers. The third temperature sensor was placed near the "2R" accelerometer (Fig. 2).

Tab. 1 The layout of the accelerometers on the Multi Degree of Freedom (MDOF) system

\begin{tabular}{|c|c|c|}
\hline No. & Name of accelerometer & Number of DOF/ Direction \\
\hline 1 & B & $33 \mathrm{Y}$ \\
\hline 2 & $\mathrm{~A}$ & $33 \mathrm{Z}$ \\
\hline 3 & $\mathrm{D}$ & $32 \mathrm{Y}$ \\
\hline 4 & $\mathrm{C}$ & $32 \mathrm{Z}$ \\
\hline 5 & $\mathrm{~F}$ & $31 \mathrm{Y}$ \\
\hline 6 & $\mathrm{E}$ & $31 \mathrm{Z}$ \\
\hline 7 & $1 \mathrm{R}$ & $6 \mathrm{Z}$ \\
\hline 8 & $2 \mathrm{R}$ & $5 \mathrm{Z}$ \\
\hline 9 & $3 \mathrm{R}$ & $4 \mathrm{Z}$ \\
\hline
\end{tabular}

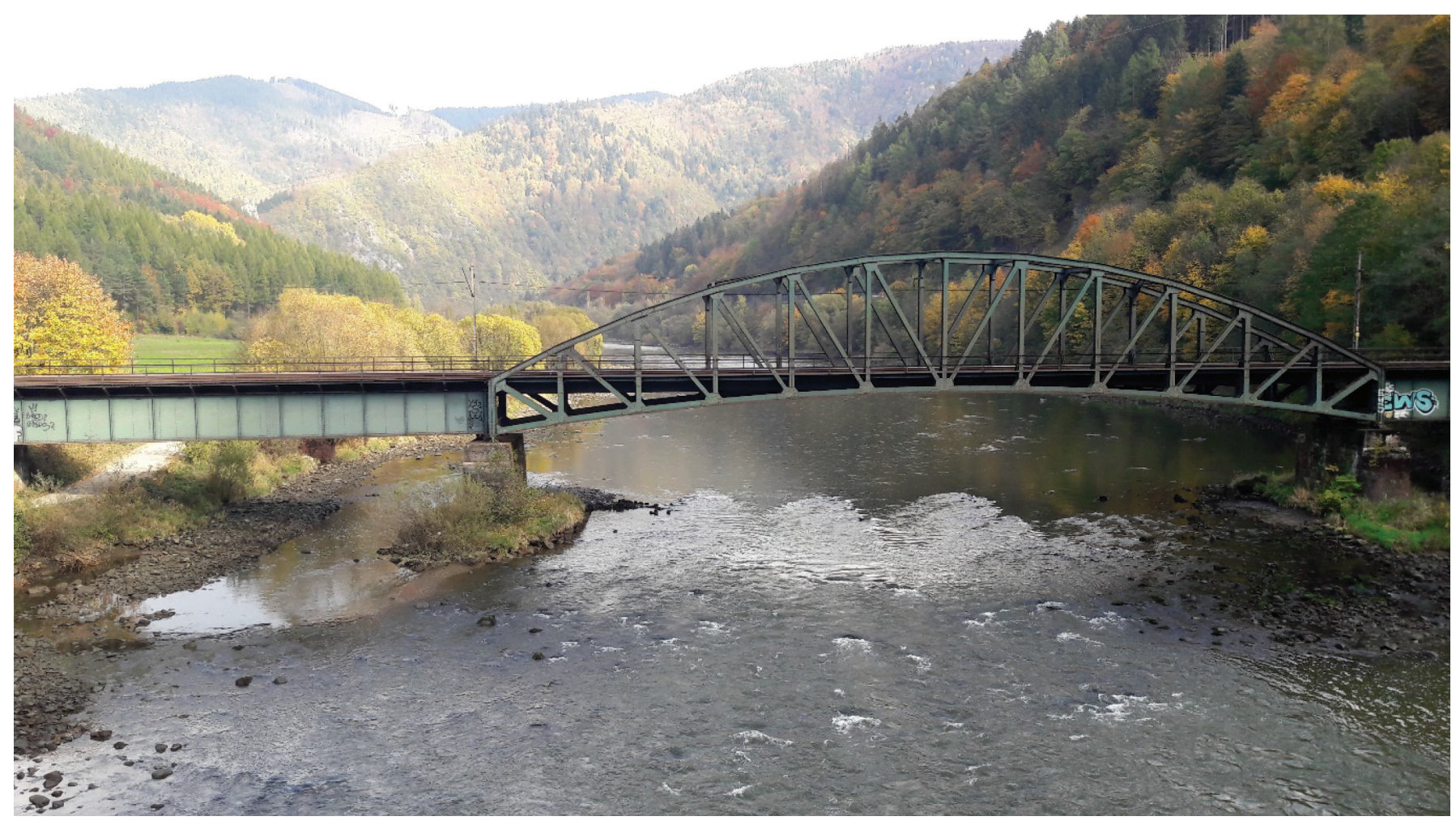

Fig. 1 The bridge structure $T 1$ (on the left T1-O3, in the middle T1-O2, on the right T1-O1) 


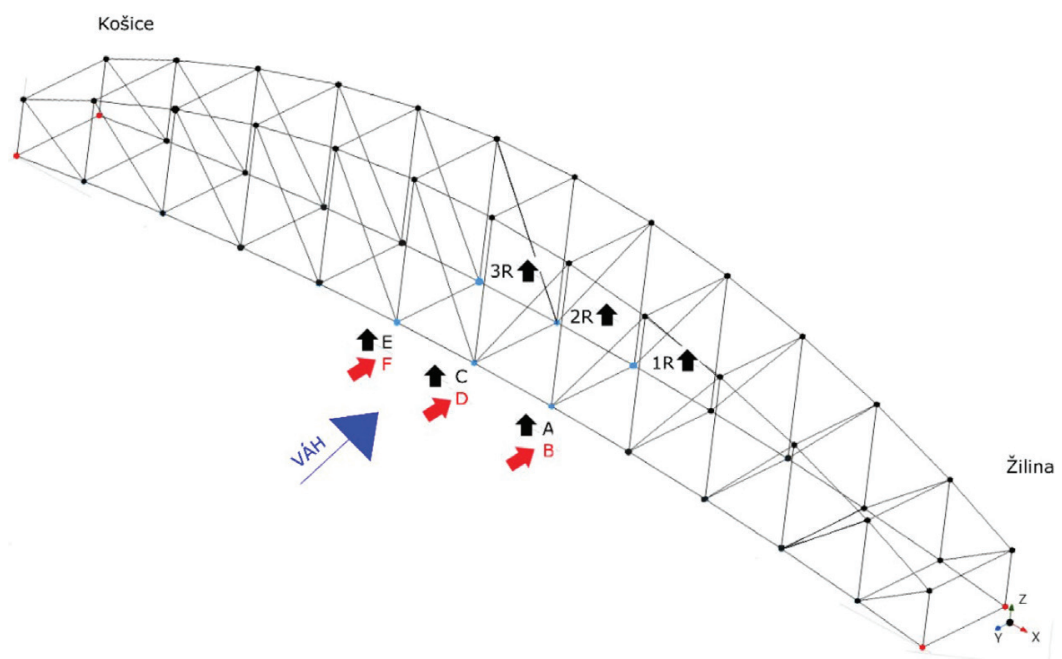

Fig. 2 The layout of the accelerometers during the measurements

\section{MODAL ANALYSIS USING STOCHASTIC SUBSPACE IDENTIFICATION}

Data were logged during the full operation of the bridge every month in the period between March and October 2018. As a result, an operational modal analysis (OMA) was performed. A time series of the acceleration was processed using ModalVIEW software. The software applies the Stochastic Subspace Identification (SSI) method as one of the methods for OMA in accordance with Magalhaes and Cunha (2011). The method belongs among output-only methods. According to Peeters and De Roeck (2001), it is powerful when input signals are unmeasured or when it is impossible to measure them, and only output data are available.

This method does not achieve exact values for the dynamic parameters, but only determines them with uncertainties. Thanks to that uncertainty, fake modes can appear. In order to distinguish between stable and unstable domains, stability diagrams (charts) are introduced. The software used allows for the preparing of stabilization charts for extracting modal parameters such as the natural frequency, the damping ratio, and matching mode-shapes. According to Mrabet et al. (2014), so-called stabilization criteria are set in order to eliminate spurious modes. They noted two types of these criteria, i.e., preliminary criteria, and stabilization criteria. The preliminary criteria are represented by (1) and (2), and (3) concerns the certainty between the two consecutive modes. If they match well (above the given threshold), the modes appear on a diagram. The equations for the calculation of the parameters to compare them with the set criteria are the following:

$$
\begin{gathered}
\left|\frac{f_{i}-f_{i+1}}{f_{i}}\right| \leq \varepsilon_{f} \\
\left|\frac{\xi_{i}-\xi_{i+1}}{\xi_{i}}\right| \leq \varepsilon_{\xi} \\
\operatorname{MAC}\left(\boldsymbol{\phi}_{i}, \boldsymbol{\phi}_{i+1}\right)=\frac{\left(\boldsymbol{\phi}_{i}^{T} \boldsymbol{\phi}_{i+1}\right)^{2}}{\left(\boldsymbol{\phi}_{i}^{T} \boldsymbol{\phi}_{i}\right)\left(\boldsymbol{\phi}_{i+1}^{T} \boldsymbol{\phi}_{i+1}\right)} \geq M A C_{\boldsymbol{\phi}}
\end{gathered}
$$

where $\boldsymbol{\phi}_{i}$ is the "i" mode-shape vector, and $\boldsymbol{\phi}_{i+}$ is the " $\mathrm{i}+1$ " (consecutive) mode-shape vector in order to calculate the Modal Assurance Criterion (MAC), see Allemang (2003) for more information about MAC. Typical values of the criteria were also stated in Lau (2007). They assumed the values were $\varepsilon_{f}=1 \%$ for the frequency stability, $\varepsilon_{\xi}=5 \%$ for the damping stability, and $M A C_{\Phi}=98 \%$ (or the difference is $\max 2 \%$ ) for the eigenvector stability.

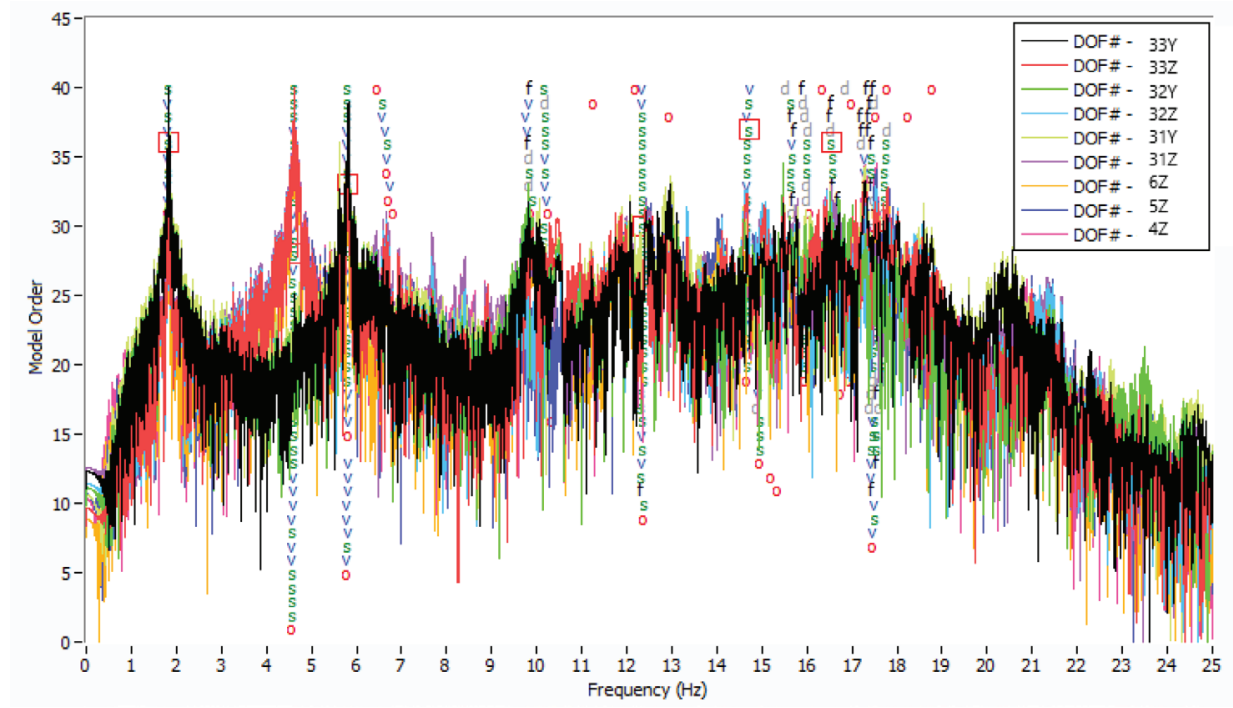

Fig. 3 Stabilization diagram using values ; and from data logged on the T2-O2 structure 
Tab. 2 The average natural frequencies on the structures measured

\begin{tabular}{|c|c|c|c|c|}
\hline No. & $\begin{array}{c}\text { Natural } \\
\text { frequency } \\
\text { T1-O2 }\end{array}$ & $\begin{array}{c}\text { Natural } \\
\text { frequency } \\
\text { T2-O2 }\end{array}$ & $\begin{array}{c}\text { Mode-shape } \\
\text { (direction of vibration) }\end{array}$ & Fig. 4 \\
\hline 1 & 1.94 & 1.89 & $1^{\text {st }}$ Horizontal (Y-direction) & a) \\
\hline 2 & 4.82 & 4.80 & $1^{\text {st }}$ Vertical (Z-direction) & b) \\
\hline 3 & 5.62 & 5.65 & $2^{\text {nd }}$ Horizontal (Y-direction) & c) \\
\hline 4 & 5.93 & 5.80 & $1^{\text {st }}$ Torsional (around X-axes) & d) \\
\hline
\end{tabular}

An example of the stabilization diagram used in the processing of the data from both structures is in Fig. 3; it is specifically for the $\mathrm{T} 2-\mathrm{O} 2$ structure. Every "s" in the square represents an identified mode-shape with a proper natural frequency (Tab. 2), which fulfils the above-mentioned criteria. All the 5-minute or more minute data sets ( $\mathrm{s}$ total of up to 40 data sets) were processed in the mentioned way previously, and the average temperature during this time was also logged. Accordingly, the dependency between the natural frequency obtained and the average temperature (ambient or structural) was prepared, and the results are presented in the following section.

a)
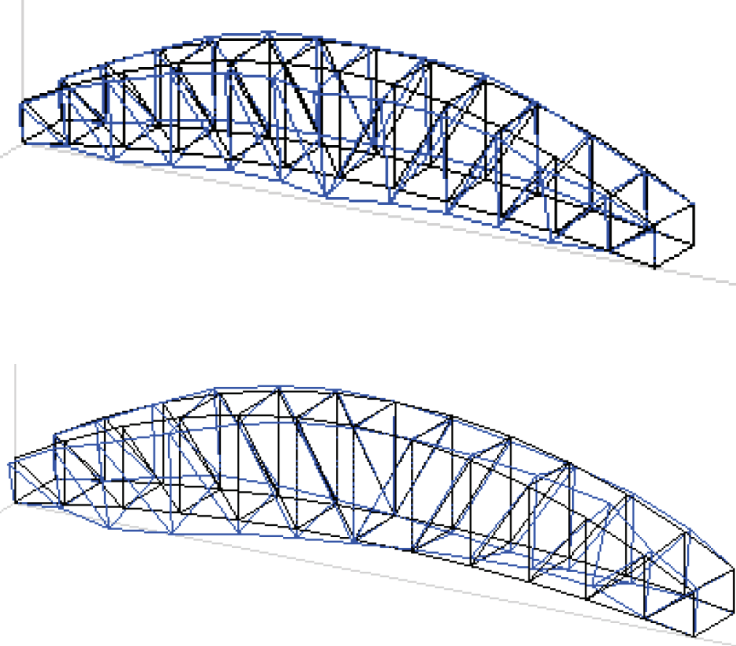

c)

Fig. 4 Identified mode-shapes: a) the first, b) the second, c) the third, and the fourth mode-shape

Tab. 3 Estimation of regression coefficients: frequency vs. air temperature (ambient)

\begin{tabular}{|c|c|c|c|c|c|}
\hline Mode-shape on T1-O2 & $\beta_{0}(\mathrm{~Hz})$ & $\beta_{t}(\mathrm{~Hz} / \mathrm{oC})$ & $\begin{array}{c}\text { Mode-shape } \\
\text { on T2-O2 }\end{array}$ & $\beta_{0}(\mathrm{~Hz})$ & $\beta_{t}(\mathrm{~Hz} / \mathrm{oC})$ \\
\hline 1 & 1.9117 & 0.00110 & 1 & 1.7376 & 0.0065 \\
\hline 2 & 4.8154 & -0.00004 & 2 & 4.3317 & 0.0192 \\
\hline 4 & 5.9898 & -0.00370 & 4 & 5.8330 & -0.0014 \\
\hline
\end{tabular}

Tab. 4 Estimation of regression coefficients: frequency vs. temperature of the structure

\begin{tabular}{|c|c|c|c|c|c|}
\hline Mode-shape on T1-O2 & $\beta_{0}(\mathrm{~Hz})$ & $\beta_{t}(\mathrm{~Hz} / \circ \mathrm{C})$ & $\begin{array}{c}\text { Mode-shape } \\
\text { on T2-O2 }\end{array}$ & $\beta_{0}(\mathrm{~Hz})$ & $\beta_{t}\left(\mathrm{~Hz} / \mathrm{oC}^{2}\right.$ \\
\hline 1 & 1.9547 & -0.0007 & 1 & 4.7457 & 0.0055 \\
\hline 2 & 4.8864 & -0.0030 & 2 & 4.3253 & 0.0176 \\
\hline 4 & 5.9392 & -0.0016 & 4 & 5.8330 & -0.0014 \\
\hline
\end{tabular}


T2-O2. The average structural temperature was calculated from two contact temperature sensors. In accordance with Xia et al. (2006), the formula which examines the goodness of fit can be written as:

$$
\rho=\frac{\operatorname{Cov}(t, f)}{\sigma_{t} \sigma_{f}}
$$

where $t$ represents the explanatory variable (temperature); $f$ is the response variable (frequency); and $\sigma_{t}, \sigma_{f}$ and $\operatorname{Cov}(t, f)$ are the standard deviations and covariance, respectively.

a)

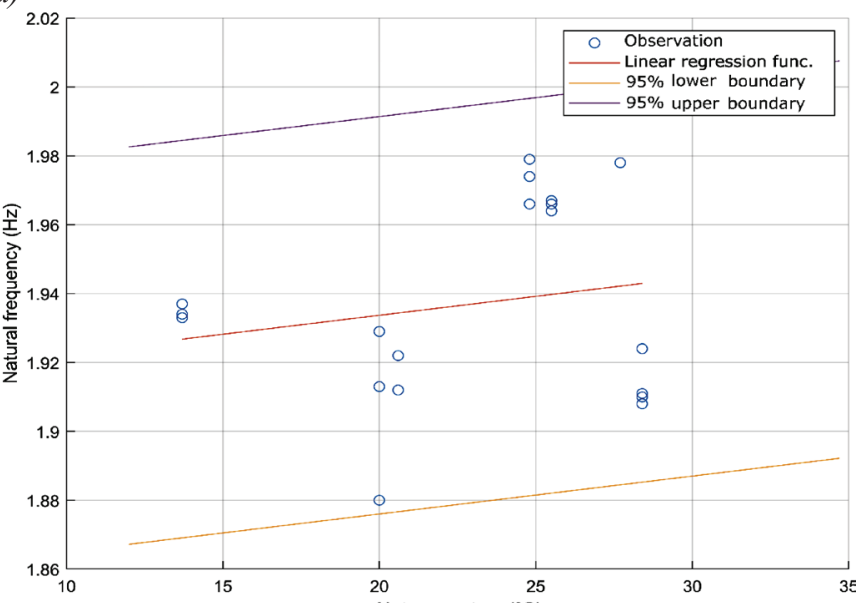

b)

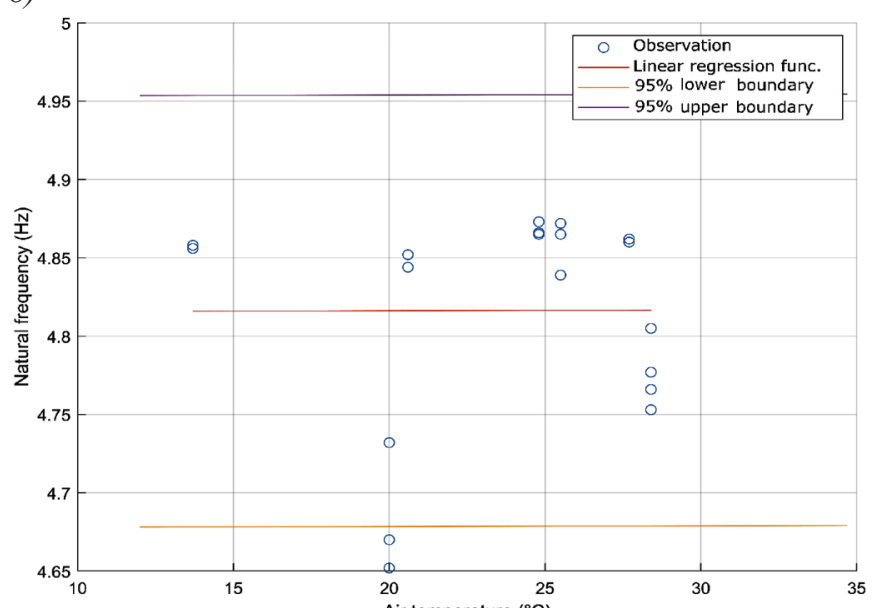

c)

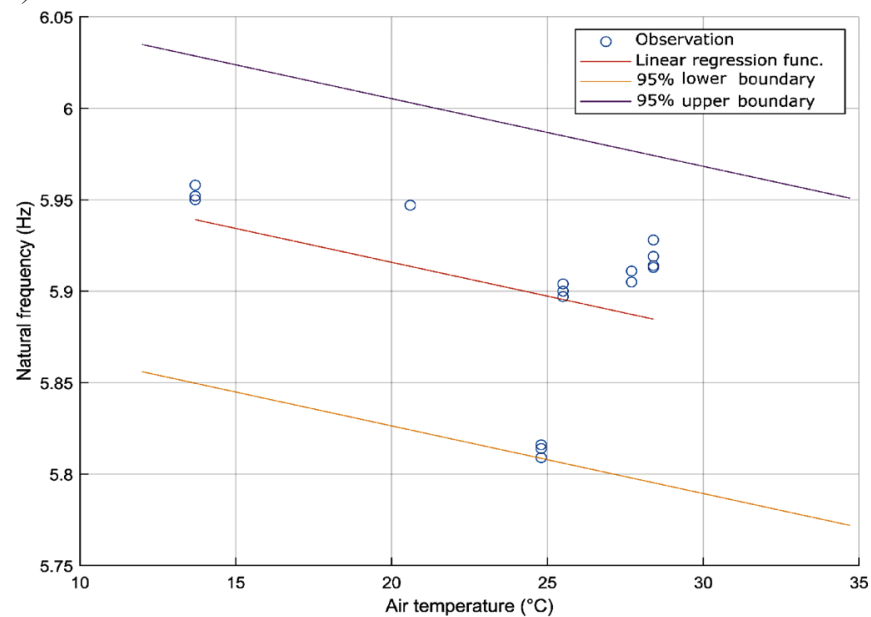

Fig. 5 Dependencies between the natural frequencies and air temperatures on the structure T1-O2: a) $1^{\text {st }}$ natural frequency b) $2^{\text {nd }}$ natural frequency c) $4^{\text {th }}$ natural frequency
Using Eq. (5), a poor goodness-of-fit was achieved from the data of the T1-O2 structure. The values were below $40 \%$. Therefore, it cannot be stated that there is a linear temperature correlation in the case of the T1-O2 structure. Similar results are also obtained if the air temperature is used in the correlation, even if the temperature of the structure is considered. Nevertheless, the linear regression functions were plotted. It can be seen from Fig. 4 that the first natural frequency increased with the increasing air temperature. The second has almost constant values. On the other hand, the fourth natural frequency a)

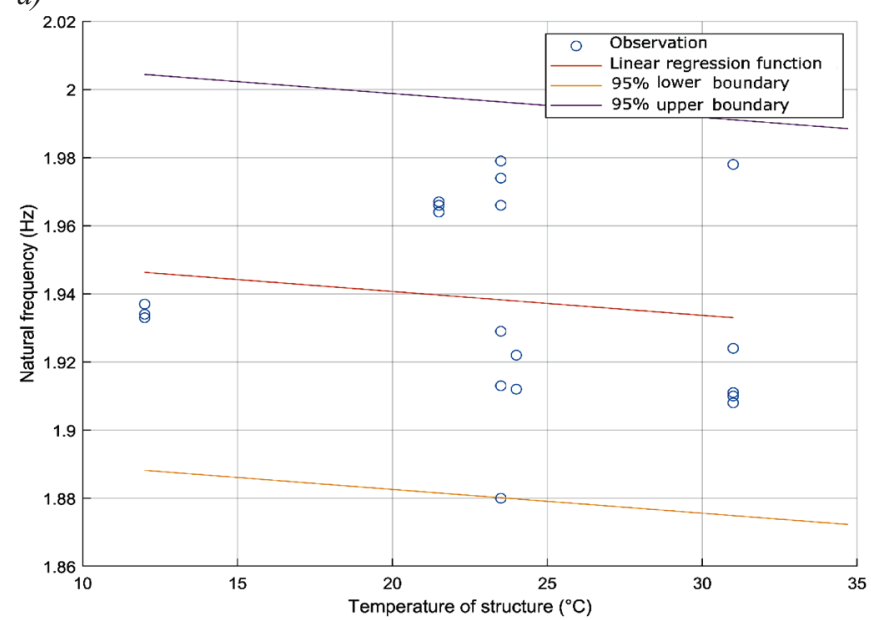

b)

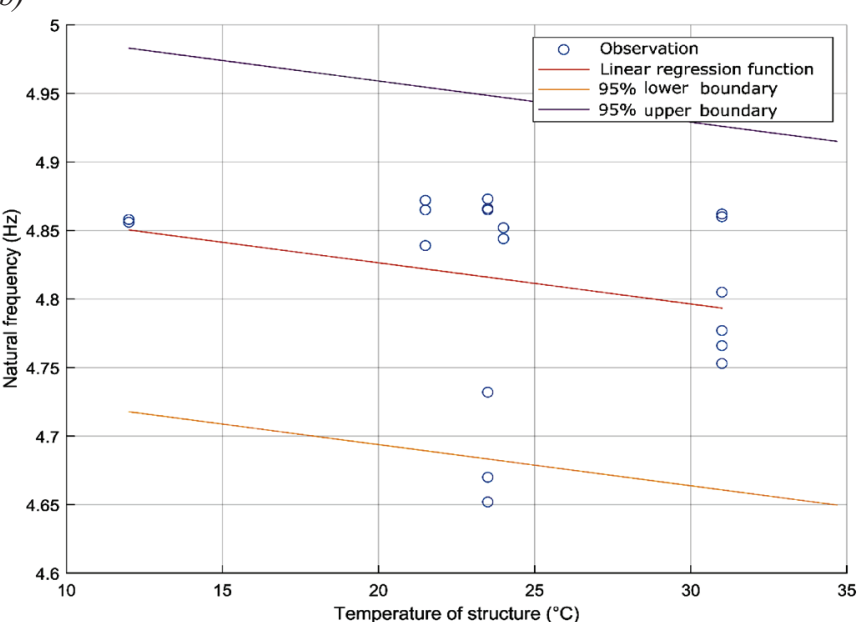

c)

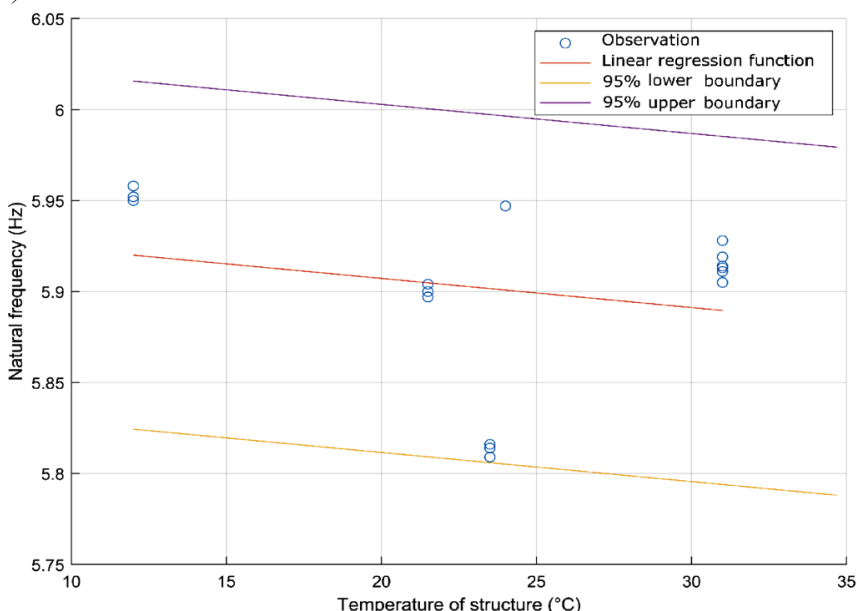

Fig. 6 Dependencies between the natural frequencies and structural temperatures on the T1-O2 structure: a) $1^{\text {st }}$ natural frequency b) $2^{\text {nd }}$ natural frequency c) $4^{\text {th }}$ natural frequency 
showed the opposite behaviour: it decreased with the increasing air temperature. In the case between the natural frequencies and temperatures of a structure, the linear regression function decreased a little for every natural frequency investigated.

On the other hand, an almost linear temperature correlation was obtained in the case of the T2-O2 structure because reached values of at least $60 \%$, but when we compare the dependencies between the

a)

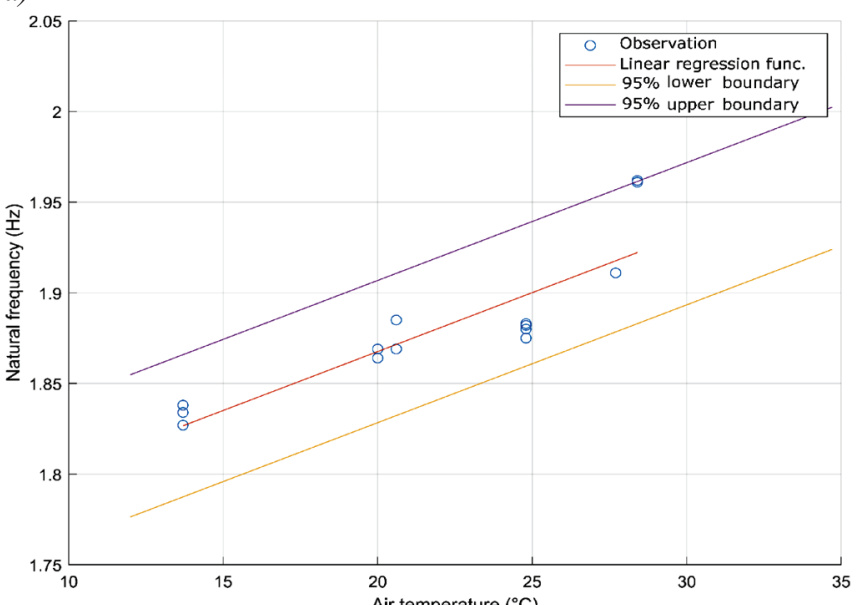

b)

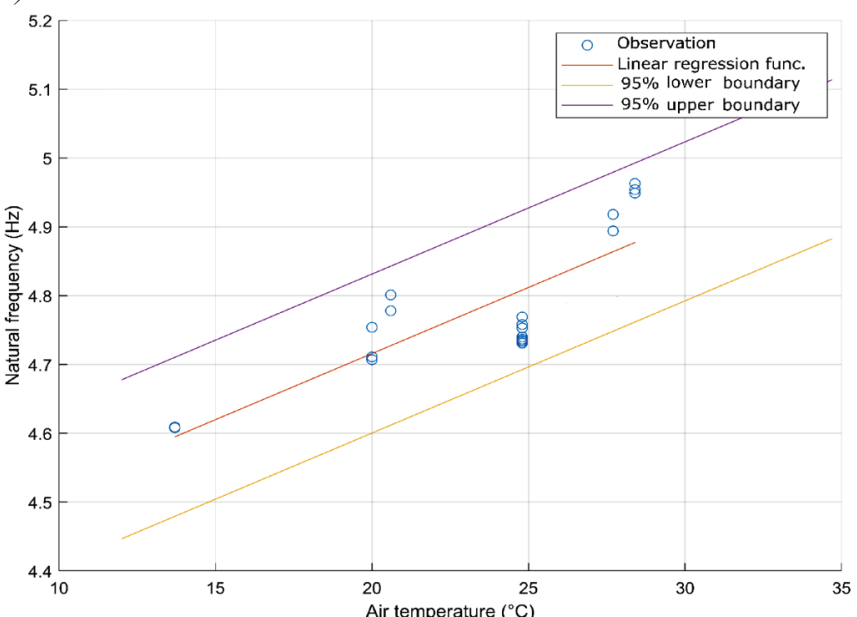

c)

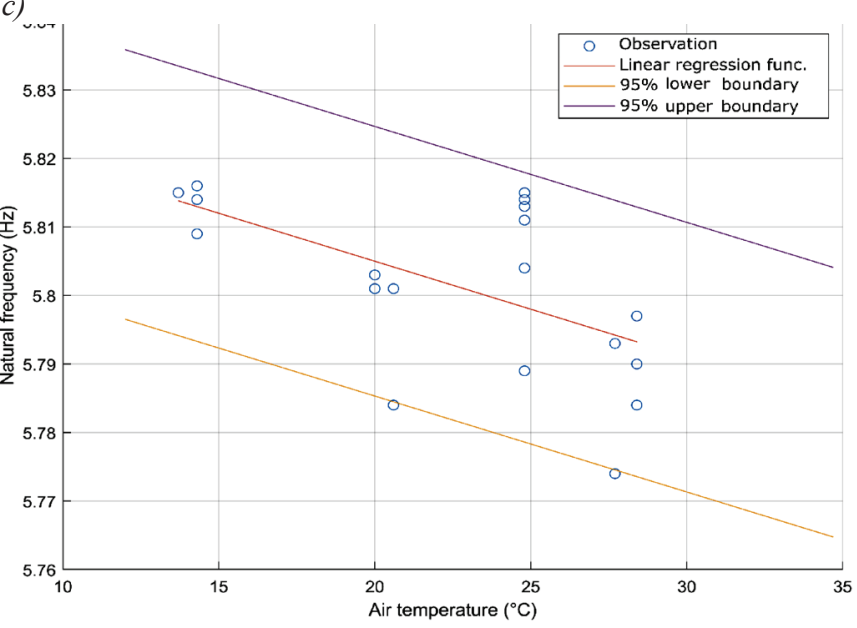

Fig. 7 Dependencies between the natural frequencies and air temperatures on the structure: T2-O2: a) $1^{\text {st }}$ natural frequency b) $2^{\text {nd }}$ natural frequency c) $4^{\text {th }}$ natural frequency natural frequencies and temperature of the structures, the goodness of fit is even better ( $80 \%$ and more). The first two natural frequencies increased with the increasing air temperature. On the other hand, the fourth natural frequency showed the opposite behaviour: it decreased with the increasing air temperature.
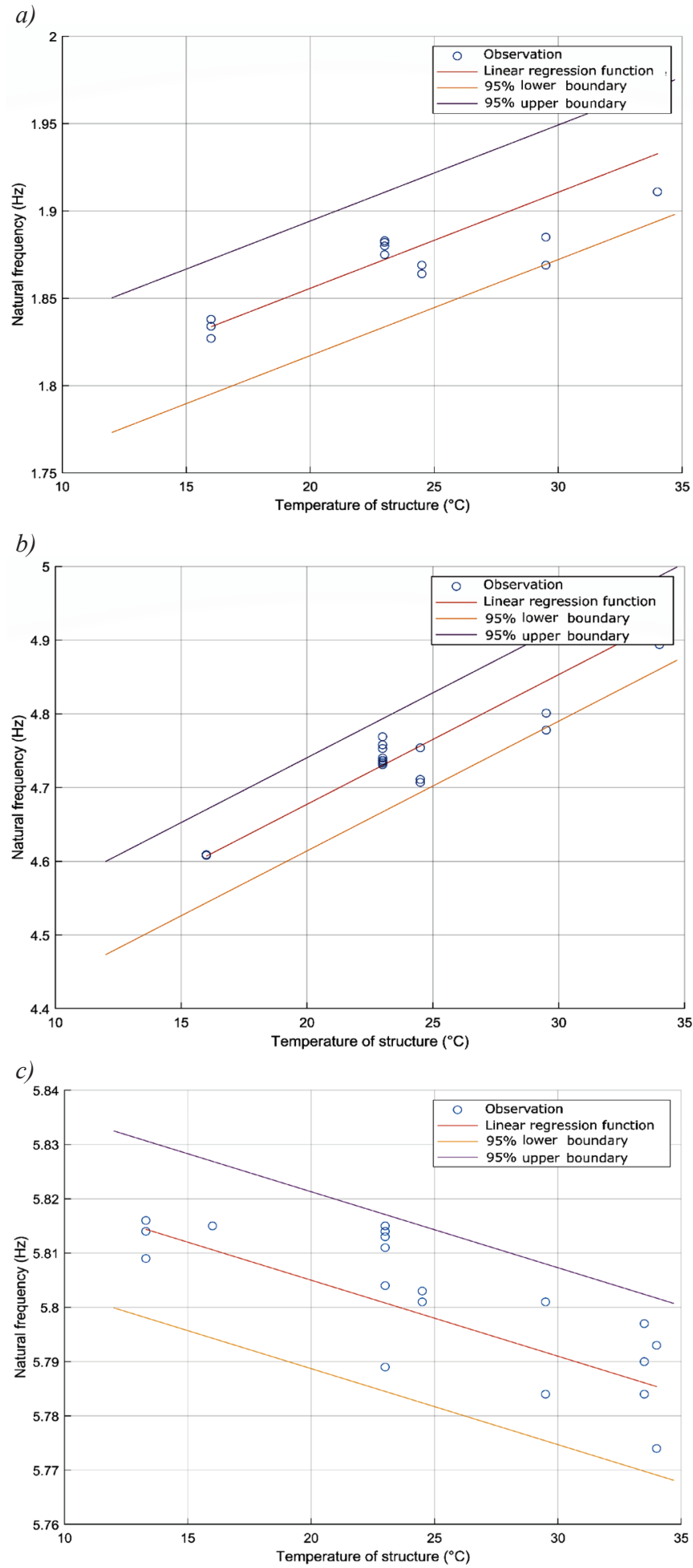

Fig. 8 Dependencies between the natural frequencies and structural temperatures on the T2-O2 structure: a) $1^{\text {st }}$ natural frequency b) $2^{\text {nd }}$ natural frequency c) $4^{\text {th }}$ natural frequency 


\section{CONCLUSIONS}

The paper deals with the impact of the temperature (ambient or structural) on modal parameters (natural frequencies), which presently represent a relatively widespread field of interest. The paper presents the outcomes of an operational modal analysis by implementing the Stochastic Subspace Identification method (SSI). The measurements that preceded the analyses were taken every month during almost one year of monitoring. As a result, the natural frequencies and corresponding mode-shapes were identified from the days with a different temperature. The results presented in the paper confirmed that the dependency of the natural frequency on the temperature cannot be generalized. Additionally, the almost identical structures had different impacts from the temperature, which further endorse the previous conclusion.

Xia et al. (2012) stated a conclusion that many researchers have found. i.e., that the natural frequency increased with a decreased temperature. This was only confirmed for the fourth natural frequency. The first two natural frequencies had opposing behaviours; the natural frequencies increased with raising the temperature. This linear behaviour was only found for the T2-O2 structure. Unfortunately, the results presented of the almost identical structure, i.e., T1-O2, could not be fitted by a linear regression function. This could be caused by a smaller number of samples.

Some recommendations for future research on the impact of the environment on modal parameters can be proposed:

- Continuous monitoring during days/weeks or months to get more data sets.

- Using more temperature sensors could be beneficial.

- Monitoring the damping ratio.

\section{Acknowledgements}

This paper has been supported by the Grant Agency of the Ministry of Education, Science, Research and Sports of the Slovak Republic VEGA No. 1/0749/19. The paper was also supported by a grant from the research program of the Slovak University of Technology - Excellent Teams of Young Researchers 2018. 


\section{REFERENCES}

Allemang, R. (2003) The Modal Assurance Criterion (MAC): Twenty Years of Use and Abuse. In: Sound and Vibration, 37(8), pp. 1423. ISSN 0038-1810.

Avendaño-Valencia, L. D. - Chatzi, E. N. - Koo, K. Y. - Brownjohn, J. M. (2017) Gaussian Process Time-Series Models for Structures under Operational Variability. In: Frontiers in Built Environment, 3. ISSN 2297-3362. https://doi.org/10.3389/fbuil.2017.00069

Behmanesh, I. - Moaveni, B. (2016) Accounting for environmental variability, modeling errors, and parameter estimation uncertainties in structural identification. In: Journal of Sound and Vibration, 374, pp. 92-110. ISSN 0022460X. https://doi.org/10.1016/j. jsv.2016.03.022

Christian, C. - Rastandi, J. I. - Lase, Y. (2019) Temperature Changes Effects to Dynamics Performances of a Pinned Supported Steel-Arch-Bridge. In: IOP Conference Series: Materials Science and Engineering, 473. https://doi.org/10.1088/1757899X/473/1/012029

Finotti, R. P. - Finotti, R. P. - Cury, A. A. - Barbosa, F. D. S. (2019) An SHM approach using machine learning and statistical indicators extracted from raw dynamic measurements. In: Latin American Journal of Solids and Structures, 16(2). ISSN 16797825. https://doi.org/10.1590/1679-78254942

Furtmüller, T. - Adam, C. (2017) Compensation of Temperature Effects in Long-Term Monitoring of a Highway Bridge located in the Austrian Alps. In: Procedia Engineering, 199, pp. 2078-2083. ISSN 18777058. https://doi.org/10.1016/j.proeng.2017.09.477

Giordano, P. F. - Quqa, S. - Limongelli, M. P (2021) Approach for Vibration-Based Damage Localization in Civil Infrastructures Using Smart Sensor Networks. In: Infrastructures, 6(2). ISSN 2412-3811. https://doi.org/10.3390/infrastructures6020022

Kala, J. - Bajer, M. - Barnat, J. - Smutný, J (2010) Experimental approach of the single pedestrian-induced excitation. In: Slovak Journal of Civil Engineering, 18(4), pp. 1-7. https://doi. org/10.2478/v10189-010-0016-2

Kita, A. - Cavalagli, N. - Ubertini, F (2019) Temperature effects on static and dynamic behavior of Consoli Palace in Gubbio, Italy. In: Mechanical Systems and Signal Processing, 120, pp. 180-202. ISSN 08883270. https://doi.org/10.1016/j.ymssp.2018.10.021

Kottegoda, N. T. - Rosso, R. (2008) Applied statistics for civil and environmental engineers. 2nd ed. Blackwell Pub, Chichester. Pp. 718. ISBN 1405179171.

Lau, J. - Lanslots, J. - Peeters, B. - Van der Auweraer, H. (2007) Automatic modal analysis. Reality or myth?. In: Proceedings of International Modal Analysis Conference. $10 \mathrm{pp}$.

Magalhães, F. - Cunha, A. (2011) Explaining operational modal analysis with data from an arch bridge. In: Mechanical Systems and Signal Processing, 25(5), pp. 1431-1450. ISSN 08883270. https://doi.org/10.1016/j.ymssp.2010.08.001

Moaveni, B. - Behmanesh, I. (2012) Effects of changing ambient temperature on finite element model updating of the Dowling Hall Footbridge. In: Engineering Structures, 43, pp. 58-68. ISSN 01410296. https://doi.org/10.1016/j.engstruct.2012.05.009

Mosavi, A. A. - Seracino, R. - Rizkalla, S (2012) Effect of Temperature on Daily Modal Variability of a Steel-Concrete Composite
Bridge. In: Journal of Bridge Engineering, 2012, 17(6), pp. 979983. ISSN 1084-0702. https://doi.org/10.1061/(ASCE)BE.1943$\underline{5592.0000372}$

Mrabet, E. - Abdelghani, M. - Ben Kahla, N. (2014) A New Criterion for the Stabilization Diagram Used with Stochastic Subspace Identification Methods: An Application to an Aircraft Skeleton. In: Shock and Vibration, 2014. https://doi.org/10.1155/2014/409298

Pápai, F. - Adhikari, S. - Wang, B. T. (2012) Estimation of Modal Dampings for Unmeasured Modes. In: Slovak Journal of Civil Engineering, 20(4), pp. 17-27. https://doi.org/10.2478/v10189012-0018-3

Peeters, B. - De Roeck, G. (2001) Stochastic System Identification for Operational Modal Analysis: A Review. In: Journal of Dynamic Systems, Measurement, and Control, 123(4), pp. 659-667. https://doi.org/10.1115/1.1410370

Shokrani, Y. - Dertimanis, V. K. - Chatzi, E. N. - Savoia, M (2016) Structural damage localization under varying environmental conditions. In: 11th HSTAM International Congress on Mechanics, Athens, Greece.

Sokol, M. - Venglár, M. - Lamperová, K. - Márföldi, M (2020). Performance Assessment of a Renovated Precast Concrete Bridge Using Static and Dynamic Tests. In: Applied Sciences, 10(17), 5904. https://doi.org/10.3390/app10175904

Sridhar, R. - Prasad, R. (2019) Static and Dynamic Responses of a Reinforced Concrete Beam Strengthened with Steel and Polypropylene Fibers. In: Slovak Journal of Civil Engineering, 27(3), pp. 44-54. https://doi.org/10.2478/sjce-2019-0021

Tian, Y. - Zhang, N. - Xia, H (2017) Temperature effect on service performance of high-speed railway concrete bridges. In: Advances in Structural Engineering, 20(6), pp. 865-883. https://doi. org/10.1177/1369433216665306

Ubertini, F. - Comanducci, G. - Cavalagli, N. - Pisello, A. L. Materazzi, A. L. - Cotana, F. (2017) Environmental effects on natural frequencies of the San Pietro bell tower in Perugia, Italy, and their removal for structural performance assessment. In: Mechanical Systems and Signal Processing, 82, pp. 307-322. ISSN 08883270. https://doi.org/10.1016/j.ymssp.2016.05.025

Venglár, M. - Sokol, M. (2020) Case study: The Harbor Bridge in Bratislava. In: Structural Concrete. 21(6), pp. 2736-2748. ISSN 1464-4177. https://doi.org/10.1002/suco.201900190

Xia, Y. - Hao, H. - Zanardo, G. - Deeks, A (2006) Long term vibration monitoring of an RC slab: Temperature and humidity effect. In: Engineering Structures, 28(3), pp. 441-452. ISSN 01410296. https://doi.org/10.1016/j.engstruct.2005.09.001

Xia, Y. - Chen, B. - Weng, S. - Ni, Y. Q. - Xu, Y. L. (2012) Temperature effect on vibration properties of civil structures: a literature review and case studies. In: Journal of Civil Structural Health Monitoring, 2(1), pp. 29-46. ISSN 2190-5452. https://doi. org/10.1007/s13349-011-0015-7

Zhou, G.D. - Yi, T.H. (2014) A Summary Review of Correlations between Temperatures and Vibration Properties of Long-Span Bridges. In: Mathematical Problems in Engineering, 2014. https://doi.org/10.1155/2014/638209 